\title{
MONITORING WHEAT CROP GROWTH PARAMETERS USING TIME SERIES SENTINEL-1 AND SENTINEL-2 DATA FOR AGRICULTURAL APPLICATION IN MONGOLIA
}

\author{
Badamgarav Gansukh ${ }^{1,3}$, Bayartungalag Batsaikhan ${ }^{2,3, *}$, Altantuya Dorjsuren ${ }^{2,3}$, Chuluunbaatar Jamsran ${ }^{1}$, Nandinbayar \\ Batsaikhan 1,3 \\ ${ }^{1}$ Mongolian University of Life Sciences, Zaisan-17024, Ulaanbaatar, Mongolia - badamgaraw.kate@yahoo.com \\ ${ }^{2}$ Institute of Geography and Geoecology, Mongolian Academy of Sciences, Ulaanbaatar-15170, Mongolia - \\ bayartungalag_b@mas.ac.mn \\ ${ }^{3}$ Mongolian Geo-spatial Association, Ulaanbaatar-15141, Mongolia
}

Commission III, TC III/10

KEY WORDS: Wheat, Crop growth parameters, Crop monitoring, Mongolia, Sentinel-1, Sentinel-2

\begin{abstract}
:
Wheat is the most important food crop in Mongolia, most of the croplands are utilizing for wheat cultivating area in the central northern region of Mongolia. The Mongolian government has several policies on the agricultural sector with wheat production in the study region has been intensified to meet people's food demands and economic development. Monitoring wheat-growing areas is thus important to developing strategies for food security in the region. In the present study, we aimed to develop an agricultural application method using remote sensing data. Sentinel-1 SAR and Sentinel-2 MSI analysis of time series data were carried out to monitor the wheat crop growth parameters. Time-series images were acquired during May 2019-September 2019 at different growth stages in Bornuur soum, Tuv province of Mongolia. The wheat crop parameters, i.e. normalized difference vegetation index, vegetation water content, backscatter value of VV, VH channels were estimated using remote sensing data with reference data as cadastre polygons of current cropland area. The results showed that provide timely and valuable information for agricultural production, management and policy-making. The agricultural application method will help to agriculture management and monitoring include crop identification and cropland mapping, crop growth monitoring, inversion of key biophysical, biochemical and environmental parameters, crop damage/disaster monitoring, precision agriculture, etc.
\end{abstract}

\section{INTRODUCTION}

Agricultural production is one of the most basic and important things in human life, which is the basic condition for human's survival and development. Using the technology of remote sensing in the agricultural sector of people can monitor the comprehensive growing condition of crops, so as to timely acquire the information on crop yields (Xiong et al., 2014).

These two indices derived from Sentinel satellite have so far not been used for crop yield prediction in Mongolia. Normalized difference water index (NDWI) as the water content of leaves and normalized difference vegetation index (NDVI).

In Mongolia, the monitoring of wheat yield at the regional and national levels are key issues for the agricultural policy and food management as well as for the economy as a whole.

In particular, crop yield estimation and the monitoring of crop production can provide fundamental information for crop producers, decision-makers in planning harvest and for agricultural development overall (Becker-Reshef et al., 2010). The agriculture sector is the second contributor to the Mongolian economy after mining (Batchuluun, A.; Lin, J.Y et al., 2010). It is the first generation attempt to estimate the wheat crop monitoring using space observation technology in Mongolia. In other studies on wheat crop growth monitoring investigate the applicability of MODIS data to adjust the WOFOST model for wheat at the potential production level in North China and to improve the simulated performance of the crop model at the regional scale (Zhang et al., 2007).
Due to its advantage of providing timely information on crop conditions during the growing season over large areas, satellite remote sensing can be used in conjunction with crop models for predicting crop yields (Wiegand et al., 1986).

Some recent studies in Mongolia, in 2010, Enkhjargal et al., 2017 used remote sensing data to calculate the soil moisture index in Mongolia and compare it with the plant index. In this study, the moisture index for April-August 1982-2002 was calculated using precipitation and potential evaporation. In the present study, it has the advantage of using detailed, multispectral data in the phenological stages of wheat cultivation. The Normalized Difference Water Index (NDWI) is a method for analyzing data for water resource assessment (McFeeters 1996). In this paper, an approach for the determination of water need of agricultural areas based on optical Sentinel-2 data is developed and validated. Best crop mapping results are achieved using spectral bands and additional multitemporal features defined from crop multitemporal NDVI profiles (Pelletier et al., 2016).

In 2019, wheat was cultivation on an area of 343515.6 hectares of land in Mongolia and 63960 hectares in Tuv province (Mongolian Statistics Office, 2019).

The primary objective of this study was to determine the best remote sensing indices in order to develop an estimation model for monitoring wheat crop growth parameters using time series Sentinel-1 and Sentinel-2 data for agricultural application in the method. Data assimilation is a method that optimally combines crop growth models with remote sensing observations, providing an effective way to improve crop yield estimation at

\footnotetext{
* Corresponding author
} 
regional scales and it is recognized as the most promising approach for crop growth monitoring and yield estimation (Huang et al., 2016; Mathieu and Neill, 2008; De et al., 2012). The overarching goal of this research application was to develop and apply a wheat monitoring framework using multispectral imagery. Objectives of this effort were to (1) map wheat extent, the water content of the crop, and coverage using high temporal frequency Sentinel-2, Sentinel-1 observations; and (2) monitor wheat using normalized difference vegetation index, vegetation water content, backscatter value of $\mathrm{VV}, \mathrm{VH}$ channels in Bornuur soum of Tuv province, Mongolia and the ability of a multisensor approach to support operational monitoring of rice at moderate scales.

\section{MATERIAL AND METHOD}

\subsection{Study Area}

This study was implemented in a planted area dominated by wheat, in Bornuur soum of Tuv province, Mongolia (Figure 1). It extends from $48^{\circ} 16^{\prime} 53^{\prime \prime N}-48^{\circ} 41^{\prime} 26^{\prime \prime} \mathrm{N}$ and $105^{\circ} 59^{\prime} 11^{\prime \prime E}$ $106^{\circ} 32^{\prime} 05^{\prime \prime E}$. The main cultivated crop is wheat (Triticum aestivum L.). The phenological stages of wheat in this area are the heading stage from early June to late August, the grain filling stage before late August, and milk-maturity in middle July. In Mongolia, wheat is generally planted in May in the year of spring and matured in September in the year.

Tuv province is the principle cropping area for and account for more than $45 \%$ of national total grain production. In this region, most of the wheat cultivated area is rain-fed cropland. Thus, determining the fluctuation of wheat yield is highly dependent on the weather condition. The region averages between have annual mean precipitation between 160 and $235 \mathrm{~mm}$. In addition, crop growing duration is short (85-115 days) in this region, and depends on location and altitude.

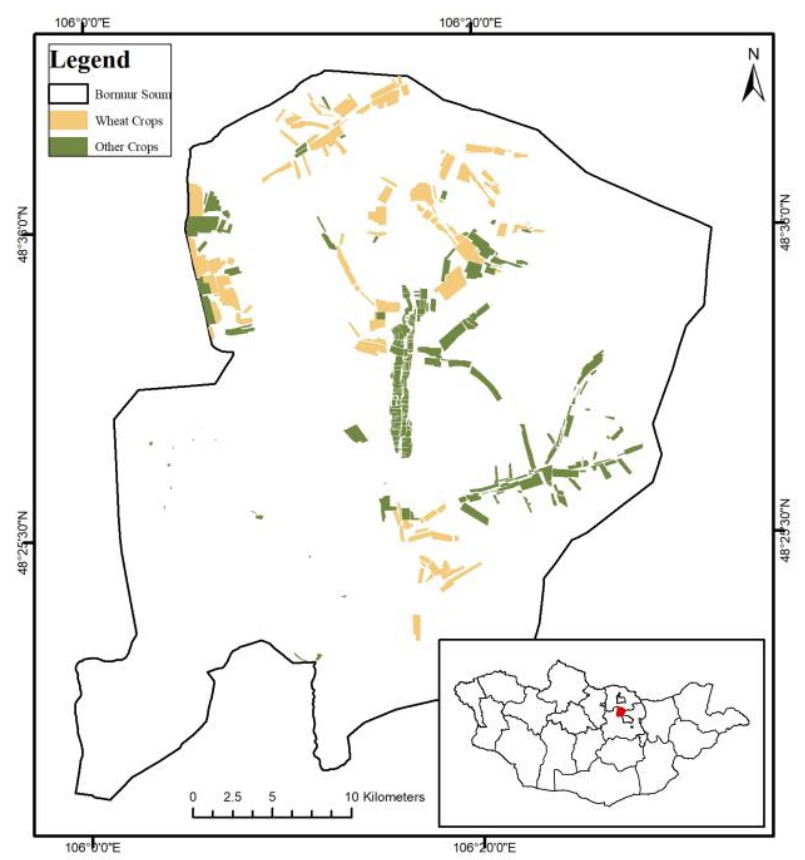

Figure 1. Location of study area and visualization of agricultural areas.

Average elevations in this region have ranged between 1821 and $872 \mathrm{~m}$. The Bornuur soum has low rainfall, relatively warm summers and low humidity. Four types of soil in Bornuur soum (Dorjgotow et al., 2003). The climate of this region is generally defined by anticyclones in the winter and summer, while spring and autumn are defined by moving from one season to the next. The main characteristics of extreme climate in Mongolia include long-lasting cold winters, occasionally unexpectedly cold summers, hot days and cold nights, high-speed daytime winds and lower-speed nighttime winds, and a lack of rainfall.

\subsection{Satellite Data and Processing}

Both the optical and radar remote sensing data used in this study (Table 1) is Sentinel-2 MSI and Sentinel-1 SAR data. Sentinel-2 is comprised of dual polar-orbiting satellites utilizing multispectral sensors to deliver high spatial and spectral resolution imagery tailored for the analysis of vegetation. The Sentinel-2 satellite is delivering new imagery of the Earth every 5 days at the equator and between 2-3 days at mid-latitudes (ESA, 2015). Consists of Sentinel-2A and Sentinel-2B equipped with Multispectral Instruments (MSI) capable of acquiring 13 bands information at different spatial resolutions $(10 \mathrm{~m}, 20 \mathrm{~m}$ and $60 \mathrm{~m})$. The number of bands and spatial and temporal resolution determines the quality of the spectral image; consequently, Sentinel-2 satellite is more suitable for remote sensing applications (Mandanici and Bitelli, 2016). A total of 9 Sentinel-2 available cloud-free image data were used to provide surface reflectance and optical indices to characterize the wheat monitoring parameters (Table 1). Sentinel-1B is the second of two C-Band Synthetic Aperture Radar (SAR) satellites of the Sentinel-1 mission, launched in April 2016 - two years after the launch of the first satellite, Sentinel-1A. In addition to the commissioning of Sentinel-1B executed by the European Space Agency (ESA), an independent system calibration was performed by the German Aerospace Center (DLR) on behalf of ESA. Based on an efficient calibration strategy and the different calibration procedures already developed and applied for Sentinel-1A, extensive measurement campaigns were executed by initializing and aligning DLR's reference targets deployed on the ground (Schwerdt et al., 2017). A total of 14 time period Sentinel-1A images were required for this study (Table 1) with Ground Range Detected (GRD), which have already been focused, multilooked, calibrated and projected in ground range. Data were terrain-corrected, normalized, and calibrated using local incidence angles and cosine correction before converting to sigma naught $\left(\sigma^{\mathrm{o}} \mathrm{dB}\right)$ for mapping and analyses. All Sentinel satellite images could be freely downloaded from Sentinel Hub, which was developed by ESA (https://scihub.copernicus.eu/). In addition, freely available satellite information analysis software is specially customized for Sentinel series.

We used indexes for our wheat monitoring study. NDVI means normalized difference vegetation index. It is defined as the ratio of the difference between the near-infrared band NIR and visible band RED and the sum of them. It can be expressed as formula (1) (Shao et al., 2016) for Sentinel-2. The normalized difference water index (NDWI, Equation (2); Gao, 1996) is an index which can be obtained from band 8A (B8A; $865 \mathrm{~nm})$ and band $11(\mathrm{~B} 11 ; 1610 \mathrm{~nm})$ of Sentinel-2 spectral data and which can be of great interest as a support to decision making in terms of harvest management of wheat. It was initially proposed for describing the status of the vegetation water content over large areas from space.

NDVI $=($ Band $8-$ Band 4$) /($ Band $8+$ Band 4$)$

NDWI $=($ Band $8 \mathrm{~A}-$ Band 11$) /($ Band $8 \mathrm{~A}+$ Band 11$)$ 


\begin{tabular}{|c|c|c|}
\hline No & Sentinel 1 / Date & Sentinel 2 / Date \\
\hline 1 & 3-May & 8-May \\
\hline 2 & 10-May & 13-May \\
\hline 3 & 27-May & 2-Jun \\
\hline 4 & 3-Jun & 7-Jun \\
\hline 5 & 15-Jun & 2-Jul \\
\hline 6 & 27-Jun & 11-Aug \\
\hline 7 & 9-Jul & 21-Aug \\
\hline 8 & 14-Jul & 31-Aug \\
\hline 9 & 26-Jul & 15-Sep \\
\hline 10 & 2-Aug & \\
\hline 11 & 14-Aug & \\
\hline 12 & 26-Aug & \\
\hline 13 & 7-Sep & \\
\hline 14 & 19-Sep & \\
\hline
\end{tabular}

Table 1. Dates of Sentinel-1 and Sentinel-2 data acquisition for the study area

\section{RESULT AND DISCUSSION}

In this section, we report the results of the proposed method. The obtained the preliminary results deduced from the Sentinel1 and Sentinel-2 are also illustrated as well as the spatial distribution of crops (Section 3.1) in Bornuur soum from May to Sep of 2019. In addition, temporal profiles of the wheat crops are presented in this section (Section 3.2) by scatter plot.

\subsection{Spatial distribution of crops}

The NDVI and NDWI for crop area with between May and September 2019 was mapped in Fig. 2 and Fig. 3. The difference image of these two results showed that represented coverage and water content of crops with remote sensing data increased values of NDVI and NDWI from 8 May to 15 September 2019. Values for the NDVI from Sentinel-2 in Bornuur soum of Tuv were increased in an approximately equidistant fashion from June to end of August. The value of NDWI for the crop water content using Sentinel-2 was relatively low until July when compared to other dates. The values were higher for from 11 August to end of August (Fig. 3 ). The reason for the low values of NDVI in May and June was a lower rainfall during this time with a low amount of irrigation groundwater well in this region. Fig. 4 illustrates the result of VV and VH channel of Sentinel-1 showed by backscatter values of each date from May to September 2019. These values are increased and declined in an approximately equidistant fashion with a distribution map of $\mathrm{VH}$ and $\mathrm{VV}$ during crop growing season. In generated VH/VV maps, light grey colours indicating the normal and favourable condition; dark colour shows unfavourable conditions, respectively. From this result, we can see that wheat yield and the phenological stage was low in growing stage months (May-June). The irrigation system is limited in Bornuur soum, most of the crops at their vegetative and reproductive stages suffer water stress due to recurrent drought. This spatial distribution of each parameter suggests the potential of Sentinel-1 (Sentinel-2) data for crop biomass retrieval. NDVI/NDWI and VH\VV decrease gradually from harvest until mid-September.

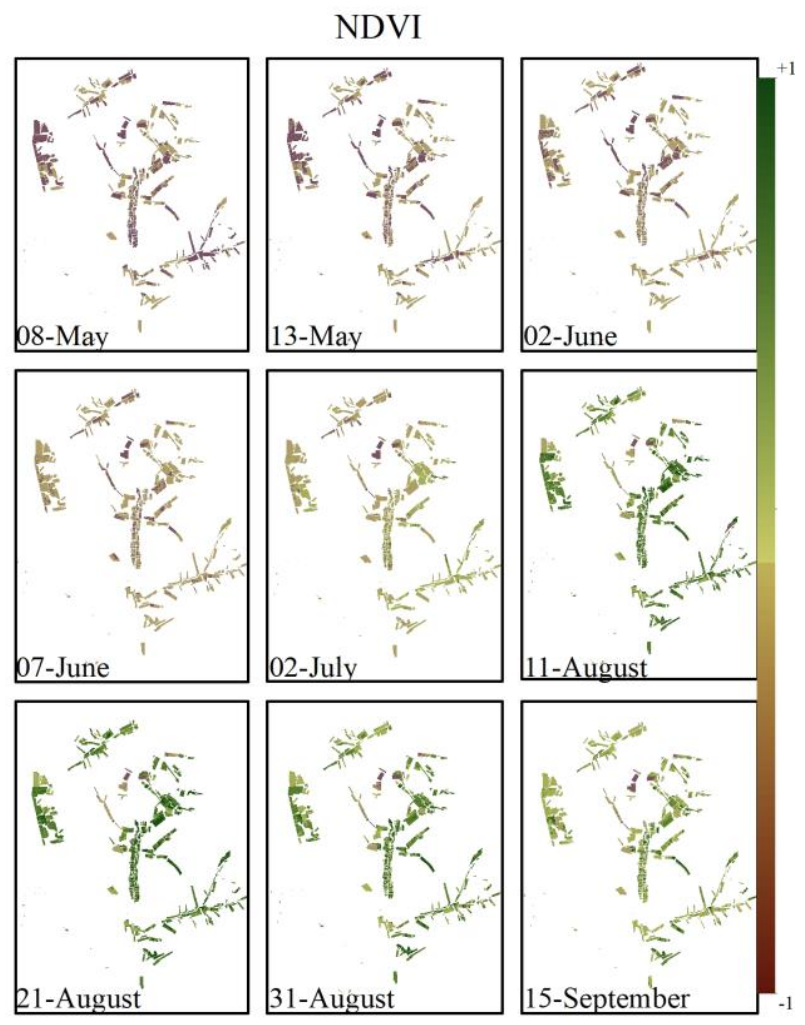

Figure 2. Spatial distribution of NDVI in Bornuur soum of Tuv province using Sentinel-2 with crop growing season of 2019.

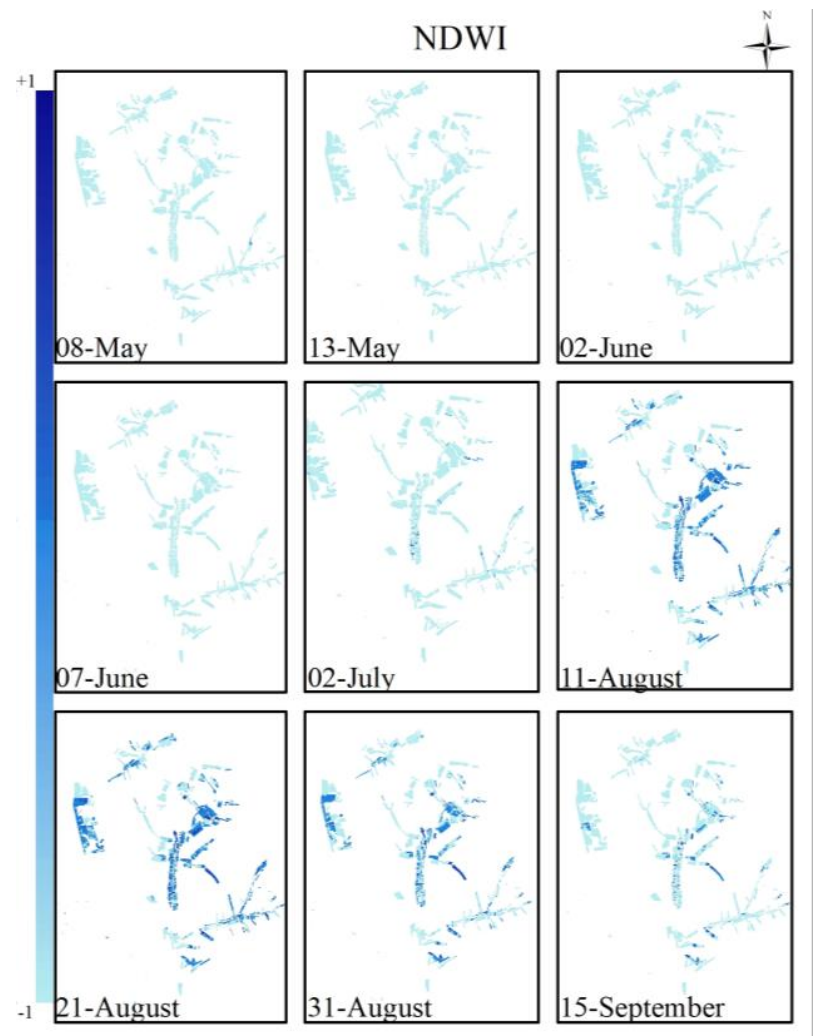

Figure 3. Spatial distribution of NDVI in Bornuur soum of Tuv province using Sentinel-2 with crop growing season of 2019. 
$\mathrm{VH}$
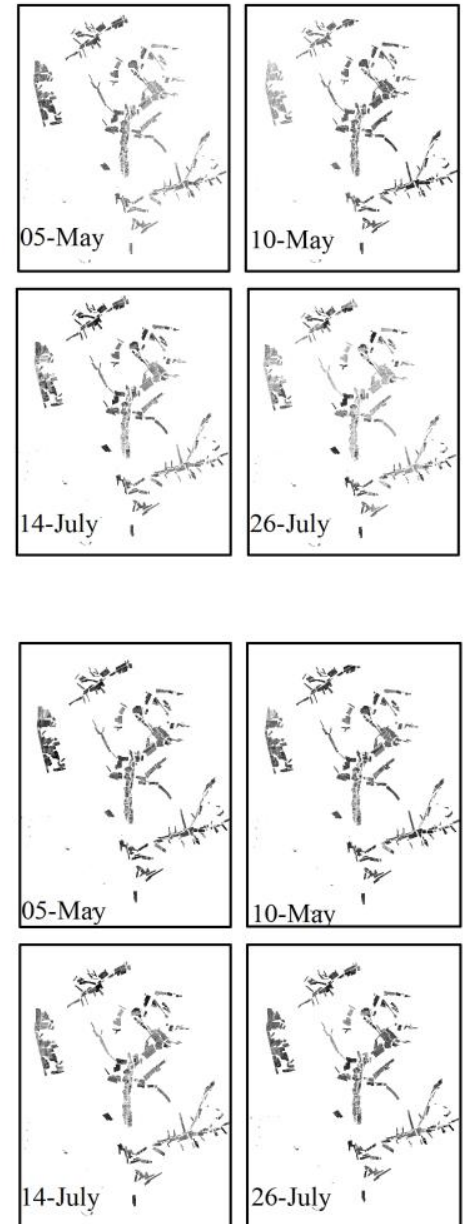
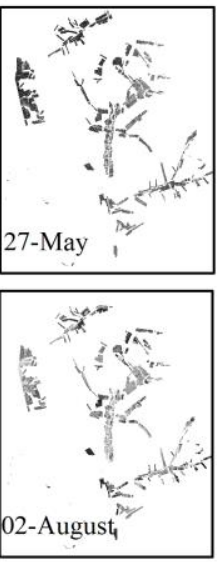
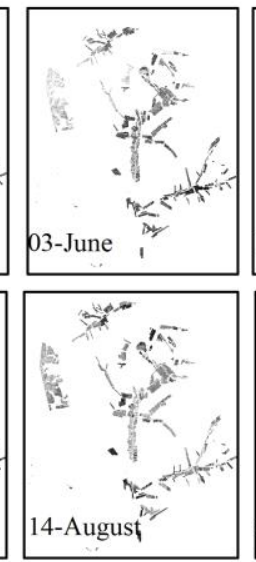

VV
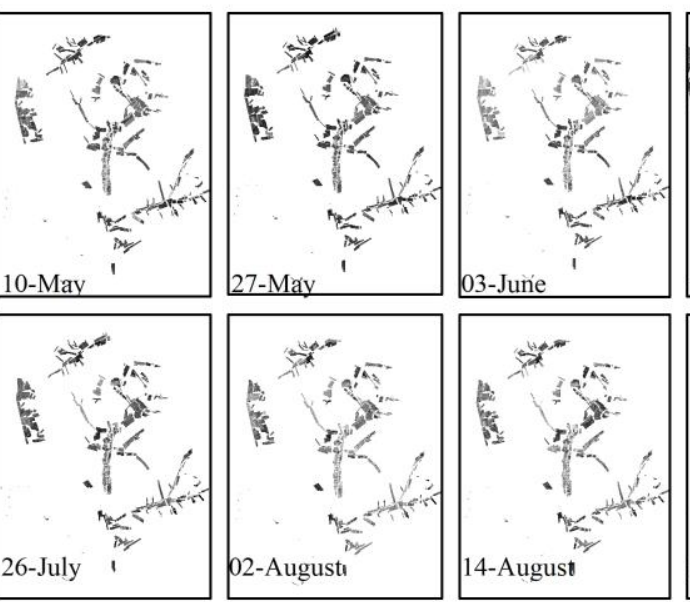
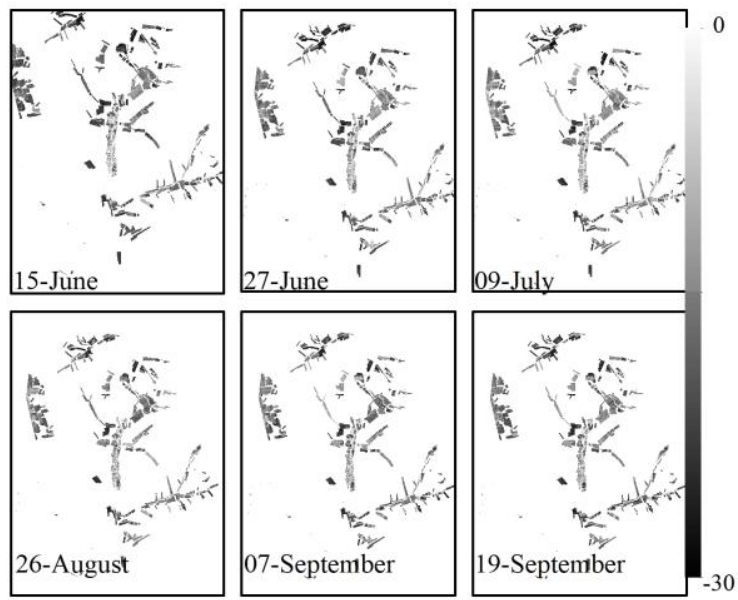

Figure 4. Spatial distribution of VH/VV in Bornuur soum of Tuv province using Sentinel-1 with crop growing season of 2019.

\subsection{Wheat crops' temporal profiles}

The majority of the spring wheat fields were large (4168 ha) and the classification accuracy for wheat of 2019 was $75 \%$. A wheat crop mask was developed from the NDVI/NDWI (Fig. 5 and Table 2) and VH/VV (Fig. 6 and Table 3) was used in the retrieval of reflectance for development of the wheat crops' temporal profiles. We extracted time series values of NDVI and NDWI in the growing season from May to September 2019 based on crop phenological stage of wheat. As shown in (Table 2), the evolution of the mean NDWI and NDVI at the growing season of 2019 shown in Fig. 5. By analysing the differences among days of wheat growing of 2019, during August, corresponding to heading stage (11 August and 21 August), and the wheat cereal has higher values in the NDVI with the mean value of 0.76 for $11 \mathrm{Aug}, 0.81$ for $21 \mathrm{Aug}$ and 0.74 for $31 \mathrm{Aug}$ than July with the mean value of 0.33 , and lower values in May than in June (Table 2 and Fig. 5). The result of NDWI and NDVI for the wheat-growing season of 2019 showed was the results, which is indicating that this index suitable for wheat phenological stage estimation in this region Fig. 5. At the beginning of July, the flowering stage causes a strong increase of NDWI and NDVI that result shown in Fig. 5, leading to high increases between July-August. At the beginning of September, the stage causes a decrease of NDVI and NDWI that result shown in Fig. 5.
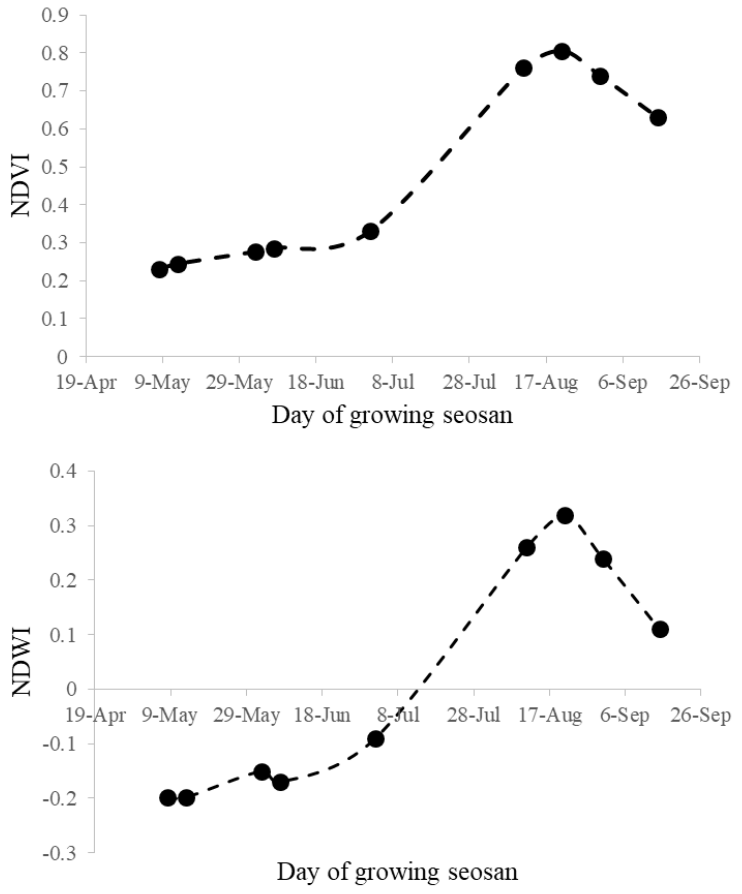

Figure 5. Times courses (a) NDVI and (b) NDWI. 


\begin{tabular}{|c|c|c|c|c|c|}
\hline Date & & Min & Mean & Max & $\begin{array}{l}\text { Standard } \\
\text { Deviation } \\
\end{array}$ \\
\hline 8-May & \multirow{9}{*}{ 方 } & 0.10 & 0.23 & 0.27 & 0.05 \\
\hline 13-May & & 0.04 & 0.24 & 0.28 & 0.06 \\
\hline 2-Jun & & 0.10 & 0.28 & 0.34 & 0.08 \\
\hline 7-Jun & & 0.12 & 0.29 & 0.34 & 0.07 \\
\hline 2-Jul & & 0.16 & 0.33 & 0.43 & 0.10 \\
\hline 11-Aug & & 0.37 & 0.76 & 0.89 & 0.07 \\
\hline 21-Aug & & 0.48 & 0.81 & 0.81 & 0.05 \\
\hline 31-Aug & & 0.30 & 0.74 & 0.77 & 0.08 \\
\hline 15-Sep & & 0.24 & 0.63 & 0.69 & 0.11 \\
\hline 8-May & \multirow{9}{*}{ 文 } & -0.31 & -0.20 & -0.17 & 0.03 \\
\hline 13-May & & -0.34 & -0.20 & -0.17 & 0.03 \\
\hline 2-Jun & & -0.32 & -0.15 & -0.11 & 0.05 \\
\hline 7-Jun & & -0.33 & -0.17 & -0.14 & 0.04 \\
\hline 2-Jul & & -0.37 & -0.09 & -0.01 & 0.11 \\
\hline 11-Aug & & -0.06 & 0.26 & 0.30 & 0.09 \\
\hline 21-Aug & & 0.04 & 0.32 & 0.36 & 0.08 \\
\hline 31-Aug & & -0.12 & 0.24 & 0.28 & 0.10 \\
\hline 15-Sep & & -0.27 & 0.11 & 0.24 & 0.13 \\
\hline
\end{tabular}

Table 2 Descriptive statistics (minimum, mean, maximum and standard deviation) of NDWI and NDVI captured at the 133 polygons of current wheat cropping area from cadastre data in the studied field, for each date, between May and September 2019.
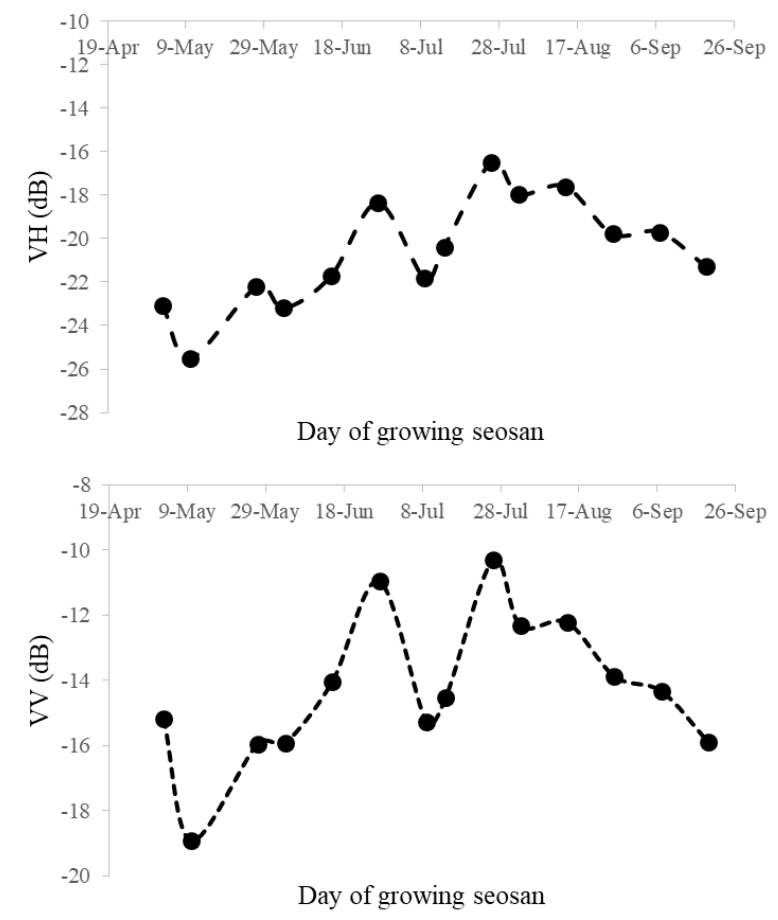

Figure 6. Times courses of (a) VH and (b) VV captured at the 133 polygons of current wheat cropping area from cadastre data in the studied field, for each date, between May and September 2019.

\begin{tabular}{|c|c|c|c|c|c|}
\hline Date & & Min & Mean & Max & $\begin{array}{c}\text { Standard } \\
\text { Deviation }\end{array}$ \\
\hline 3-May & \multirow{14}{*}{3} & -23.14 & -15.17 & -7.84 & 2.61 \\
\hline 10-May & & -25.80 & -18.92 & -8.80 & 2.70 \\
\hline 27-May & & -24.17 & -15.94 & -8.71 & 2.65 \\
\hline 3-Jun & & -23.65 & -15.92 & -7.88 & 2.65 \\
\hline 15-Jun & & -22.70 & -14.04 & -12.55 & 2.52 \\
\hline 27-Jun & & -20.69 & -10.95 & -9.73 & 2.47 \\
\hline 9-Jul & & -23.57 & -15.27 & -7.94 & 2.68 \\
\hline 14-Jul & & -23.79 & -14.52 & -13.25 & 2.57 \\
\hline 26-Jul & & -17.79 & -10.30 & -8.72 & 2.21 \\
\hline 2-Aug & & -20.03 & -12.32 & -10.45 & 2.08 \\
\hline 14-Aug & & -18.73 & -12.22 & -10.58 & 1.94 \\
\hline 26-Aug & & -21.26 & -13.87 & -11.59 & 2.12 \\
\hline 7-Sep & & -22.19 & -14.33 & -6.52 & 2.39 \\
\hline 19-Sep & & -24.05 & -15.89 & -7.45 & 2.43 \\
\hline 3-May & \multirow{14}{*}{$\stackrel{\square}{>}$} & -32.18 & -23.05 & -18.68 & 2.40 \\
\hline 10-May & & -34.35 & -25.51 & -16.79 & 2.91 \\
\hline 27-May & & -29.27 & -22.22 & 16.64 & 2.72 \\
\hline 3-Jun & & -32.16 & -23.19 & -16.26 & 2.89 \\
\hline 15-Jun & & -29.89 & -21.72 & -19.92 & 2.63 \\
\hline 27-Jun & & -27.52 & -18.36 & -17.16 & 2.78 \\
\hline 9-Jul & & -29.91 & -21.83 & -14.66 & 3.22 \\
\hline 14-Jul & & -27.98 & -20.37 & -13.60 & 2.72 \\
\hline 26-Jul & & -24.59 & -16.51 & -15.04 & 2.58 \\
\hline 2-Aug & & -26.99 & -17.96 & -16.40 & 2.47 \\
\hline 14-Aug & & -25.47 & -17.60 & -16.18 & 2.13 \\
\hline 26-Aug & & -29.11 & -19.78 & -13.24 & 2.37 \\
\hline 7-Sep & & -28.79 & -19.69 & -12.41 & 2.91 \\
\hline 19-Sep & & -30.34 & -21.29 & -13.20 & 2.87 \\
\hline
\end{tabular}

Table 3 Descriptive statistics (minimum, mean, maximum and standard deviation) of $\mathrm{VH}$ and $\mathrm{VV}$ captured at the 133 polygons of current wheat cropping area from cadastre data in the studied field, for each date, between May and September 2019.

Despite inter-month differences, the general trend consists of wheat in VH and VV backscatter values at the beginning of spring, reaching a maximum value during 10 May, followed by a clear decrease, which is mainly related to the beginning of cultivation as a start from 10 May with ploughing soil. Fig. 6 obtained strong and significant incenses on values of $\mathrm{VH}$ and VV between June and August. Backscatter values of VH and $\mathrm{VV}$ are responsive to changes in both the water content and the biomass of crops. The values as VH/VV are decreased in MidJuly, this pattern, typical of dryland ecosystems, reflects the conjugation of the effects of air temperature and precipitation and their influence on SMC, PMC and vegetative vigour. 


\section{CONCLUSION}

The study paves a way for crop monitoring Tuv province in Mongolia. We have explored remote sensing indices in decade and month intervals. We used that there are two indices as NDWI and NDVI with backscatter values of VV/VH that are very relevant for wheat monitoring. This study has found that the NDWI and NDVI are the best indices for Mongolian crop monitoring. The NDWI, NDVI was mainly indicated as an effective tool for soil, and vegetation moisture conditions and in vegetative areas, which was determined by the NIR and SWIR bands. It is recognized as the most promising approach for crop growth and pest control, monitoring and yield estimation. Furthermore, Remote sensing and satellite technology will attendance an important role in the agricultural sector in Mongolia. Developed wheat crop growth monitoring in Tuv province of Mongolia using time-series Sentinel 1 and 2. In Mongolia, the application of remote sensing methodology in agricultural policy and practices is in its nascent stage. This was the first of stage time a multi-spectral image based on remote sensing indicators was used to monitor wheat-growing parameters in Bornuur soum of Tuv province, Mongolia which is the main wheat-producing region.

\section{ACKNOWLEDGEMENTS (OPTIONAL)}

I am grateful to my supervisor, Dr. Bayartungalag Batsaikhan for his helpful comments on the manuscript. Moreover, I am grateful to the reviewers whose comments helped to improve the quality of the manuscript remarkably. I am also grateful to ISPRS travel grant and publication fee from the ISPRS Foundation. This work was funded by the Mongolian Foundation for Science and Technology for their financial support with the project of "Key Technology Research \& Development and Application Demonstration of ChinaMongolia Pasture Monitoring based on Multi-source Remote Sensing Data Fusion". Sentinel data was provided by the European Space Agency (ESA).

\section{REFERENCES}

Becker-Reshef, I., Vermote, E., Lindeman, M. and Justice, C., 2010. A generalized regression-based model for forecasting winter wheat yields in Kansas and Ukraine using MODIS data. Remote sensing of environment, 114(6), 1312-1323.

Batchuluun, A. and Lin, J.Y., 2010. An analysis of mining sector economics in Mongolia. Global Journal of Business Research, 4(4), 81-93.

De Wit, A., Duveiller, G. and Defourny, P., 2012. Estimating regional winter wheat yield with WOFOST through the assimilation of green area index retrieved from MODIS observations. Agricultural and forest meteorology, 164, 39-52.

Dorjgotov, D. 2003. Soils of Mongolia. Ulaanbaatar: Admon Publisher

Gao, B.C., 1996. NDWI-A normalized difference water index for remote sensing of vegetation liquid water from space. Remote sensing of environment, 58(3), 257-266.
Huang, J., Sedano, F., Huang, Y., Ma, H., Li, X., Liang, S., Tian, L., Zhang, X., Fan, J. and Wu, W., 2016. Assimilating a synthetic Kalman filter leaf area index series into the WOFOST model to improve regional winter wheat yield estimation. Agricultural and Forest Meteorology, 216, 188-202.

Wiegand, C.L., Richardson, A.J., Jackson, R.D., Pinter, P.J., Aase, J.K., Smika, D.E., Lautenschlager, L.F. and McMurtrey, J.E., 1986. Development of agrometeorological crop model inputs from remotely sensed information. IEEE Transactions on Geoscience and Remote Sensing, (1), 90-98.

McFeeters, S.K., 1996. The use of the Normalized Difference Water Index (NDWI) in the delineation of open water features. International journal of remote sensing, 17(7), 1425-1432.

Mathieu, P.P. and O'Neill, A., 2008. Data assimilation: From photon counts to Earth System forecasts. Remote sensing of environment, 112(4), 1258-1267.

Mandanici, E. and Bitelli, G., 2016. Preliminary comparison of sentinel-2 and landsat 8 imagery for a combined use. Remote Sensing, 8(12), 1014.

Natsagdorj, E., Renchin, T., Kappas, M., Tseveen, B., Dari, C., Tsend, O. and Duger, U.O., 2017. An integrated methodology for soil moisture analysis using multispectral data in Mongolia. Geo-spatial Information science, 20(1), 46-55.

Pelletier, C., Valero, S., Inglada, J., Champion, N. and Dedieu, G., 2016. Assessing the robustness of Random Forests to map land cover with high resolution satellite image time series over large areas. Remote Sensing of Environment, 187, 156-168.

Schwerdt, M., Schmidt, K., Tous Ramon, N., Klenk, P., YagueMartinez, N., Prats-Iraola, P., Zink, M. and Geudtner, D., 2017. Independent system calibration of Sentinel-1B. Remote Sensing, 9(6), 511.

Shao, Y., Lunetta, R.S., Wheeler, B., Iiames, J.S. and Campbell, J.B., 2016. An evaluation of time-series smoothing algorithms for land-cover classifications using MODIS-NDVI multitemporal data. Remote Sensing of Environment, 174, 258-265.

Tuvdendorj, B., Wu, B., Zeng, H., Batdelger, G. and Nanzad, L., 2019. Determination of Appropriate Remote Sensing Indices for Spring Wheat Yield Estimation in Mongolia. Remote Sensing, 11(21), 2568.

Wiegand, C.L., Richardson, A.J., Jackson, R.D., Pinter, P.J., Aase, J.K., Smika, D.E., Lautenschlager, L.F. and McMurtrey, J.E., 1986. Development of agrometeorological crop model inputs from remotely sensed information. IEEE Transactions on Geoscience and Remote Sensing, (1), 90-98.

Zhang, L., Wang, S., He, Y., Ma, Y., Zhuang, L. and Hou, Y., 2007. Winter wheat growth simulation under water stress by remote sensing in North China. 401-410.

Xiong, D., 2014. Crop growth remote sensing monitoring and its application. Sensors \& Transducers, 169(4), p.174. 